ISSN 1112-9867

\title{
DOUBT, THE POSSIBILITY OF REFUSING THE SPIRITUAL ESSENCE IN THE HUME PHILOSOPHY
}

\author{
F. Lazemi
}

Department of Persian Literature and Foreign Languages, the University of Tabriz, Tabriz, Iran

Published online: 18 July 2016

\begin{abstract}
Hume rises in a period of time that world was strongly influenced by growth of science. But, since this experience-oriented philosopher is affected by Barclay, he focuses on science experimental aspect a lot and believes that all human knowledge is derived from intuitive impression. He recourses to a general principle for creating this new base in human knowledge and includes that all human mental containers is made of impressions and imaginations and the provenance of them is intuitive experience. After issuing this general principle, Hume examines his beliefs for human knowledge like belief to the principle of causality, belief in spiritual essence $^{1}$ and so on. He finally concluded that none of these beliefs do not come to the human intuitive experience. So, the verdict to existence of these beliefs is invalid by recourse to sense or sagacity. But when human treads into the field of action and routine, he/she cannot deny the existence of these beliefs. In this article we try to discuss about Hume skepticism and his definition of essence by referencing to the treatise about human nature book first, second, fifth, sixth seasons and sixth season forth chapter and the study of human understanding book first, second and third chapters of eighth and twelfth seasons; and demonstrate that Hume Cannot be a full-blown skeptic even by denying spiritual essence.
\end{abstract}

Keywords: doubt, spiritual essence, impressions, imaginations, Hume.

Author Correspondence, e-mail: author@gmail.com

doi: http://dx.doi.org/10.4314/jfas.v8i2s.134 


\section{INTRODUCTION}

Though, philosophers have always wanted certainty, they often osculate to skepticism in reaching certainly, so that many of develops in the realm of epistemology is indebted challenges that skeptics have been supplied. As we know, the first effecting skeptics were sophist, so that an important section of Socrates, Plato and Aristotle efforts spent in refusing with them. The second period of skepticism in the medieval formed in the conflict of science and faith shape. But the skepticism that was created in a new era in terms of the reasoning depth and strength was in the different level and place. Among the philosophers of new era, the names of two men are in inextricably with skepticism, one of them is French Rene Descartes and another one is English David Hume.

Although Descartes begins his philosophy with doubt, but overall problem and main object in his thought is cognition system reconstruction in the manner that is completely certitude. The doubt in an instrument for him to put aside prejudices and sense perceptions and reach to certainty for him.

In contrast, Hume, who is typically one of the Descartes heirs, or at least one of his influenced people, emerges as an empiricist philosopher in the eighteenth century, when science was dominated and he begin his philosophy to provide a new method of science. For this reason, he divided human perception to impressions and imaginations. Hume objective was a research about quality of human comprehension. For this reason, he divided human perception to impressions and imaginations. And accordingly, he attains this overall verdict that if human doesn't have impression about a thing, of course, will not have any imagination of that thing.At this point, he tries to review his beliefs such as belief in the principle of causality, belief in existence, belief in outside world existence, belief in human existence, belief in existence of external objects in the universe, belief in corporeal substance existence and finally belief in corporeal substance existence, but he concludes that because some of these beliefs do not come in intuitive experience, he could not have any impression and finally any imagination about them. So, the existence of these matters verdicts is disputable.

Accordingly, the famous passage is that Hume is skeptical from his constitution. But, the exact explore in the works of this philosopher, whose works read less in Iran and some deal his name is under sunshade of Kant name, creates instability in recent famous believe. Hence, we try to examine the truth of famous passage by reviewing Hume doubt nature. 


\section{The nature of the Hume doubt}

Hume from a certain point of view in a limited and distinct position comments about skepticism. From this perspective, for the first time in his most important work, i.e. the treatise about human nature, in seasons one and two of the fourth session, and also at the end of the first part of the book, and again in research on human understanding book, eighth and twelfth seasons of the first, second and third he had worked on this issue. But from the more precise and more philosophical perspective, in the form of discussions, attitudes and arguments of Hume's there is skeptical mood.

In addition to the sense known errors that the formers considered, he represents a major mistake as to accept the existence of the outside world that the reason refuse to accept it. Indeed, he believes there is a natural stimulus that enforce human to trust his/her senses and so to trust his/her senses-independent universal presence. Hume in the twelfth chapter of the research from human understanding book reviews doubt in senses. He believes skeptics have always emphasized the unreliability of the senses and have mentioned reasoning and examples about this, but many of the arguments are old arguments in his opinion, because they are not reliable. But there are profound theorems about sense error that we cannot forget them easily (Hume, 1740). Hume's On the basis of the Treatise book refers to the greatest errors of the senses error based on the existence of the outside world acceptance. But this belief is a belief that we cannot prove it by philosophical argument or through intellect, but here psychological phenomenon called habit puts into the field. Habit is a natural incentive in human essence that forces him/his to accept the existence of the outside world and this is what human reason has refusal to accept it. But which factors lead us to believing the existence of the body? In order to answer these questions in the first he separates two issues, first, why even things are not ready to our attentions, we insist that they are always ready and have continuous presence, and second, why we consider them distinct from our mind and perceptions? In response to this question, he expresses that, because their existence depends on my mind and perceptions. Indeed, if we look carefully, we can see that these two questions are about same thing and that is human mind and perceptions. So, we can say that these two questions are related anyhow. Because if human precept it or not, the objects will continue their continuum and contiguous presence. Then, in fact the objects also will be distinct from human mind and perceptions. In fact, by answering to first question, the second question is answered spontaneously (Jonathan, 1999). After this stage, 
Hume has raised another question and that is whether the belief is about continuum and contiguous presence and yet our senses or it is about human mind? At first, Start his work with senses.

He says from the beginning that our senses can not be the reason of things and objects existence. Because, when we stop sensing verb, this believe cannot be in our essence. In addition, our senses do not understand objects distinguish of our sensing impressions. For example, when we look to our hand or desk, we just understand our impressions due to senses, not own hand or table. So, if senses are our reason to the presence of external things, in this case our senses should convey the impressions such as that presence for us. In addition we should also belong to our senses and we should be in sensing perception subject status for apparent senses. While it is impossible in Hume opinion, i.e. the senses cannot teach about its own belongings and in fact its own (Hume, 1740).

Senses deception is a reason that our perceptions appear as a distinct matter from us to us. But Hume would not continue this issue more. So, by this reason he comes back to previous problem, i.e. to appoint this problem that our senses cannot be our belief reason to presence objects. In addition to sense, from Hume point of view, reason also cannot be our belief reason to presence objects or lead us to believe mind-independent things existence. Since in Hume opinion, philosophical theorems about mind-independent objects augments is not useful for the general public even on the assumption of integrity, but only for some of the properties would be useful. In addition, philosophy teaches us that everything emerges in mind is just perception, so it cannot inferred the existence of subject independent of the mind and mind perceptions. By assumption of such deduction existence, this deduction will be casual and for its reliability we should observe permanent continuity of that objects with these perceptions. But this is not possible because we cannot issue from perceptions and compare them with something other than itself. So far, Hume believes that proof of continued existence for objects is impossible for both mind and sense (Fogelin, 2009). But he said that all of us (Humans) would like to have continued existence and separate from the mind and perception, the belief that is product of imagination. After a short test in "treatise about human nature" book, Hume believes that since objects have two features: stability and symmetry, we find such specter or illusion. For example, mountains and trees always appear to us in a same form so that if we see them frequently, a change cannot be found in our imaginations. That's why we always have equal and same impressions. But he 
admits that this stability cannot be completely dominant because this is not true in impressions whether mild or severe, voluntary or involuntary. It is here that he introduces symmetry and admits that if there is not stability, so some kinds of adaption are still dominant. However, because specter placed within the chain of thought, it will progress even the subject is wasted. Like the ship that moves by oars, it will go ahead without new buoyancy force. So mind goes so far to see the stability and symmetry impressions of that as to believe that the continued existence of objects as it assumes that discrete perceptions is interconnected by real creatures that we are unaware about it. Thus, in Hume belief we would like to give the illusion about the continued existence of objects in this form; because this illusion is from memory bright impressions and compel us that the continued existence of objects. Because belief is a bright imagination.

Hume after outline doubt in sense follows his job about abstract reasoning. Hume likes to induct these error arguments by citing to existent error in human force at use time. Accordingly, sciences such as arithmetic, geometry and algebra are supposition sciences and no mathematicians would be able to reach complete certainly. Accordingly Hume begins his doubts to degrade certain about the likelihood of sciences such as arithmetic, geometry and algebra with this title that we cannot find any case in sciences such as mathematics, arithmetic and geometry, for example about numbers. The reason for this is dealt with infinity value. It means that surely we can not find a number that it ends on it and then a number starting. For this reason, these sciences should have reduced from certainly level to probable level. So Hume with his work reduces all of human cognition to probability, thus begins his skeptical arguments about the wisdom (Scott, 1987).

However, he evaluated the reliability of the wisdom of these possibilities. He does this by relying on human intelligence and experience. Thus he compares the judge that man acquires in each argument of his/her nature and based on his/her wisdom and experience measures its accuracy or inaccuracy and by considering the existence of error in past and probability of error existence in future, he will obtain his decision making scale accuracy and finally he will add the result that he will find from comparison of his nature decision making and understanding nature with his understanding (Avnur, 2015). Up to this point, Hume has attained the confidence related to the possibilities and added it to his wisdom. In the next phase we will speak about the possibility of error in this truth and reliability of power estimation. To know the existence of errors, he figures 
out tests on certain beliefs that wisdom attains them by confidence and believes that we should never assume that human is powerful at first because the belief is a probably thing that subject to an infinite number of defects and thereby, after the imposition of infinite doubts, nothings will be left of it (Fogelin, 2009). However, when humans are examined for their beliefs, after passing the test over and over again to infinity, they will find degradation and destruction of all beliefs.

Hume knows these beliefs come from feeling that the reason is not able to destroy it. When we want to make a judgment and sentence about the truth or falsehood of something (belief), we will not have any standard. Or in the other word by what criteria can we say on what we believe is correct or not? We do not have any standard when we want to judge about an issue (a belief) truth or untruth or by which reason we could say our belief is correct or not? From Hume point of view our judgment doesn't have any standard and just because of the nature of our creation and requirements is involuntary. This is where Hume has raised the habit (Edvard, 1998). Hume said that the ideas would come through habit and if it is not correct there is no belief in human, because when we spot a belief, it will be destroy by infinitive reputation and so on to infinity. In this case, first belief totally destroyed and nothing remains of it and thus has no faith left us. For this reason, Hume knows belief as a sense that is from habit and experience and is not just a simple act and do not give an error.

\section{Distinction between doubt in realm of thought and doubt in the realm of action}

After this stage, Hume asks a question that if it is possible that our judgments about something (a belief) completely acknowledge or deny it, in this case, how much of certitude about that subject is enough for us? To answer this question Hume says that when we do infinite iterations on our first belief, we attain to a new belief that is also a possibility and this possibility is attained through thought and senses and it can be in an infinitely repeat reduced and destructed and so on to infinity. New question that arises is how much of confidence is sufficient for daily and philosophy life? (Hume, 1999). To answer, Hume believes that in this state mind deviates from its normal path and cannot find himself fit with previous habits or find himself compatible with his inconsistency causes. In this case the principles that are valid for the mind creates different effects in mind with principle that mind find them incorrectly (Buckle, 2001).

In Hume opinion, doubt is under the rule of wisdom and comes from it. The more powerful wisdom makes doubt principle stronger. Hume noted that we should never trust to our skeptical arguments unless they can destroy all of our wisdom and beliefs. However, Hume has raised 
visible-oriented theory, a realistic theory about nature of perception, a sense that be classified under realistic theory and a theory that is not skeptical. Typically in the epistemological books, they ascribed this theory to Hume this theory is not skeptical theory in any way. According to this theory, "perceptions is characteristic that seems some of those things» (Buckle, 2001). It means everything that has most importance in sensory perception and is a test of reality, are the same phenomena that would present in mind.

Hume's some ideas that are traditionally considered to be skeptical, indeed, are not skeptical and nowadays most of Epistemologists believe it. For example, his referring to the psychological weakness of man in the attainment of knowledge has been emphasized repeatedly by virtue epistemologists (for example: Ref: Zagzebsky, 1392: 135). Hume says: "None of the weaknesses of human nature can be generalized to call testimony of others as much as what is commonly gullibility, or very easy faith. This weakness explains easily through similar effect (Hume, 1999).

\section{Doubt in the spiritual substance essence}

To explain doubt in the spiritual substance essence in Hume philosophy, we should have a quick look to Hume's position about principle of causality. We have seen that he began his philosophy by examining his beliefs. Hume, in his treatise on human nature book divided all of entire human mind into impressions and ideas, and states that sensory experience is the origin of all of them (Hume, 1740) and he reminded that if we do not have any impression about a thing, therefore it will not have any imagination about that thing. After Hume specifies imaginations fountain, he meets an imagination that is not result of any impressions and it is also an imagination and indeed its causality imagination. Therefore he introduces this question that "Now I find a thing that is not the result of any impressions but also is imagination". In this case, Hume says that impression of causality should be the result of relation between objects and now we should try to discover this proportion. However causality is not an experimental impression of empirical, but it discovers from relationship between the proportion of external objects that are present in the mind. So, it can be said that in obtaining it external experience is underlie of human mind association, but this is not a certainty principle.

Hume refers to two important facts in casual respect that are Propinquity and time priority (Hume, 1740). But these two conditions are not enough. Therefore the third condition is required. In Hume opinion pursued of essence events in numerous times cannot be causality relationship evidence and provenance. It means that if we observe that phenomenon a occurs 
after phenomenon $b$ we cannot say that phenomenon $a$ is reason of phenomenon $b$, unless we show that there is an essential relationship between accruing phenomenon a after phenomenon $b$ (Hume, 1740). But here the Hume question is that necessary relationship imagination arises from which impression? After a long investigation he concluded that this imagination is not provable to intuition and theorem. So the only other provenance is experience. But, after a short time he says: such a belief is not just based on experience and repetitious symmetry observation with two events pursuit, rather in addition it is based on prospect and expectancy that repetition symmetry and two events pursuit creates two events in us. It means everything is based on this firm belief that nature always acts steady. This result seems harmless. Also when we ask that why we believe to its accuracy and on that time also to answer to this question there are just two options, wisdom or experience. But in this case like previous case wisdom cannot help us. So, the just option that would remain for us is experience and nature proves that it would act steady. Thus this steady will continue in this way. However, Hume does not stop in his skeptical results, because there is a belief in our presence about nature act uniformly even it is verifiable or not. That's why Hume tries to determine the origin of this belief. He expressed that this belief is the product of mind habit (Hume, 1740). Hume asks causation exclusively with sense and experience and because he doesn't find it, he denies its existence of the principle. He accepts its parts experience by loyalty to originality base on after the other and finally he achieves complete skepticism of course in opinion area. According to what was said about Hume belief in the principle of causality, his position on other issues can be diagnosed.

Hume allocates the forth section of treatise about Human nature to essence discussion. $\mathrm{He}$ generally denies essence concept, i.e. relation of each imagination to an impression based on cognition that he elected. Hume says that because we don't have any imagination about spiritual essence, hence we cannot find an impression hitherto imagination. Hitherto, Hume another reason in denying spiritual essence is hided in this question that what the offspring is of unity delusion and sensual extension? But Hume cannot loose from his/her belief to oneself essence in this section continuance such as related section to this causality. At the same time that we saw, we plan a series of questions by Hume. At this stage, as foreign bodies Hume first stage of human belief that brings the senses. He discussed we cannot say that our imagination of spiritual essence is obtained through one of the senses because otherwise it (spiritual essence) should had color, sound, smell, etc., respectively. While it doesn't have the essence of none of these cases. 
In the next step brings us to Hume's discussed about wisdom. While according to his principles, reason also fails to acknowledge the spiritual essence, in this case, the third stage of reason discussed by Hume. In this case, the essence would be nothing except a collection of simple ideas that reason made them compound and join and gave them specific name "essence"..

It means because of this reason, we consider the existence of the soul as something stable that makes our reason wrong. The objects that are multiple and discrete at the same time though to be continuum connected, and have relation and connection with each other and because of this our relation disregards their multiplicities and we assume them as a unit. The relation and juncture in Hume opinion have three types: resemblance, causation and proximity that are discussed only about two types of self-similarity and causality (Hume, 1740). According to this Hume principle, that we are nothing but a collection of perceptions, our memory creates perceptions similar past perceptions. This similarity makes them all one and we know that our current perceptions are the same as our previous perceptions that have remained intact over time. Similarly, there is a causal between our perceptions. Our perceptions have influence to each other and we make all of them as illusion that its components are constantly changing. In the other word one goes, another one comes to. Hume in this part of the Treatise on human nature book resembles the spiritual essence into a world where different members have been united with bilateral ties and expand with new people join. This world remains in his entirety ad unity, although his men are changed. The spiritual essence in its entirety illusion one thing, although if our perceptions and impressions changed. Hume discusses about memory here, because it always keeps our perceptions alive In Hume's point of view, it is possible to understand the reasoning concept and also similarity relation by memory power. Because its memory that gives us reason and effect imagination in a unit time and so we can create us reason and effect relation among them.

In other words, if there is no memory, there isn't any relation about effect imagination after the disappearance of reason imagination. About the similarity, the memory is unity creator and its relation is the same. At the end, Hume predicate an issue to oneself expansion, that he discussed about it in forth section of treatise about human nature book and knows constructions between cognitions offspring of oneself expansion delusion. In his view, this link leads to integrity and imagination combine simplicity and lack of plurality and thereby becomes simple self-delusion (Hume, 1740). What has been said, referring to the skepticism of Hume in the thought area. But when Hume comes to practice and everyday life like other people, he cannot deny the existence 
of these beliefs (Fogelin, 1985).

\section{CONCLUSION}

We can conclude that Hume cannot be a real and complete skeptic even denying the spiritual essence by surveying verdicts and Hume opinions about doubt in this paper Because as it was shown, besides the presence of signs about Hume doubt illusory, we are witnessing the fact of his own language in everywhere of Treatise of human nature book as Hume's the first and the most important book, that most of its chapters are around doubt and skepticism topic. Hume actually accepts universal doubt and skepticism breaker.

\section{REFERENCES}

- David Hume. (1740). A Treatise of Human Nature, edited by L. A. Selby-Bigge, 2nd ed. revised by P. H. Nidditch. Oxford: Clarendon Press.

- David H. An Enquiry concerning Human Understanding, edited by Tom L. Beauchamp Oxford/New York: Oxford University Press, 1999.

- Buckle S. Hume's Enlightenment Tract: The Unity and Purpose of "An Enquiry concerning Human Understandin”, gOxford: Clarendon Press, 2001.

- Robert J. Fogelin. Hume's Skeptical Crisis: A Textual Study, Oxford University Press, 2009.

- Robert J. Fogelin. Hume's Scepticism in the "Treatise of Human Nature", London: Routledge and Kegan Paul, 1985.

- Yuval A. Excuses for Hume's Skepticism, Philosophy and Phenomenological Research, 2015

- Arnold N. Scott. Hume's Skepticism in the Treatise of Human Nature, Journal of the History of Philosophy, 1987.

- Dancy J, \& Sosa E(eds). a companion to epistemology, 1999.

- Flage E. Daniel D.hum's theory of mind, 1990.

- Craig E. encyclopedia of philosophy, routledge, general, 1998, 8. 
How to cite this article:

Lazemi F. Doubt, the possibility of refusing the spiritual essence in the hume philosophy. J. Fundam. Appl. Sci., 2016, 8(2S), 1915-1925. 